\title{
Moderating Effects of Contextual and Individual Factors on the Relationship between Cultural Precedents and Marketing- Related Norms
}

http://doi.org/10.21272/bel.3(3).39-46.2019

Masoud Moradi

$\mathrm{PhD}$, Assistant Professor, Department of Marketing, Texas State University, San Marcos, Texas, USA

\section{Fereshteh Zihagh}

$\mathrm{PhD}$, Assistant Professor, Department of Economics and Business Analytics, University of New Haven, New Haven, CT, USA

\begin{abstract}
This paper discusses the effect of corporate culture precedents (i.e., job satisfaction, training, organizational justice, and ethical leadership) on marketing norms acceptance or violation (i.e., unethical practices of 4Ps) in an organization. In the analysis of behavior precedents, this paper analyzes the subsequent stage that predicts ethical behavior: corporate culture precedents. Moreover, the proposed model encompasses the moderating effects of contextual (i.e., ethical optimism, organizational factors, and industry factors) and individual (i.e., moral philosophies, demography, and personality traits) factors on the relationship between cultural precedents and marketing norms acceptance. Based on the discussions, the paper offers a set of propositions regarding the impacts of cultural precedents on marketing norms and the moderating roles of individual and contextual factors. Investigating the predictors of engaging in unethical acts in 4Ps leaves room for research since the attention to the topic has not been balanced and except for promotion and advertisement, other marketing mix variables (i.e., product, price, and distribution management) have attracted limited research focus. According to the proposed model, managers should focus on job satisfaction, training, ethical leadership and organizational/distributive justice to increase the chance of acceptance of marketing norms in the organization. Managers should also be aware of the role of moderating factors such as demography and personal traits of the people who they work with. By considering these roles, managers can better implement marketing norms in the organization.
\end{abstract}

Keywords: Ethical Culture, Cultural Precedents, Marketing-Related Norms, Individual Factors, Contextual Factors.

JEL Classification: L20, M14, M31.

Cite as: Moradi, M., Zihagh, F. (2019). Moderating Effects of Contextual and Individual Factors on the Relationship between Cultural Precedents and Marketing-Related Norms. Business Ethics and Leadership, 3(3), 39-46. http://doi.org/10.21272/bel.3(3).39-46.2019.

(C) The Authors, 2019. This article is published with open access at Sumy State University.

\section{Introduction}

Organizations utilize codes of ethics to promote ethical behavior. However, codes of ethics have proved to be quite inefficient in reinforcing ethical behavior. Only 35\% of studies report that codes control unethical behavior (Kaptein and Schwartz, 2008). The reason for such inefficiency is the lack of managements' support for enforcing the codes. Codes are not effective unless managers reward good behavior and punish employees defying them (Lau et al., 2017). Vitell et al. (1993) conclude that ethical climate of organizations does not influence individuals' acceptance of marketing-related norms. If this observation generally holds true, it means that ethical climate of the firms, the way is defined by Vitell et al. (1993) and is used in many research, cannot predict specific marketing-related conducts and we cannot readily generalize the current literature's findings of climate-behavior links to marketing employees with the purpose of explaining their specific (un)ethical conducts. However, there is another concern that the single item they used to measure the ethical environment of an organization may be inadequate to capture the association. Ferrell and Ferrell (2009) note that "an ethical sales function should not operate as a silo independent from organizational culture as a whole". Thus, research needs to be done to shed light on the association between corporate 
ISSN (online) - 2520-6311; ISSN (print) - 2520-6761

culture and marketing department culture. Mayer (2014) highlights the need for analyses at levels beyond individual ones and the need for the use of non-self-reported measures.

In this paper, we contribute to the literature by developing a model that investigates antecedents and precedents of (un)ethical behavior with respect to marketing-related norms. We also discuss the moderating effects of both individual and contextual factors on the acceptance of marketing-related norms in organizations. The proposed relationships will be explored and developed in a series of propositions for future research. Our proposed model helps managers improve the ethical practices of 4Ps (i.e., price, product, place, and promotion) by focusing on the culture of their organizations as predictors of those practices. Moreover, our model offers the moderating factors (i.e., individual and contextual factors) to understand how the effect of organizational culture on marketing norms can be strengthened or weakened. By considering these roles, organizations can better implement the marketing norms and, as a result, they can move toward success in terms of stakeholders (e.g., customers and employees) satisfaction.

\section{Literature Review and Theoretical Perspective}

Researchers have attempted to develop theoretical models in the marketing ethics filed (Ferrel and Gresham, 1985; Hunt and Vitell, 1986, 1993; Trevino, 1986). These descriptive models have not been safe from criticism. For instance, Schlegelmilch and Oberseder (2010) express that "Papers of the normative tradition, such as Laczniak and Murphy (2006), have not achieved such a high rate of citation despite their high relevance. Hence, in future, more room should be given to a discussion of normative marketing ethics that establishes guidelines for marketers rather than investigating their behavior". In contrast, Hunt (1991) emphasizes the need for positive models that explain the situation as it is rather than provide us with guidelines regarding what we should do. Keeping in line with this vantage point, we can start developing models for specific marketing-related conducts to be of more relevance to the practical field compared to general ethics models. The objective will be describing the ethics-related issues to find out how to modify them. Thus, a group of researchers believe that, although individual characteristics are determinants of ethical behavior, the role of contextual factors is more important from a practical viewpoint (Hoogenboom et al., 2013), mainly because the work environment is more easily controlled than individual values. Consequently, trying to understand the link between ethical behavior and individuals' decision making, a great body of research has been dedicated to the study of two environmental factors: 1. ethical culture, 2. Ethical climate. It has been demonstrated that supervisors and managers can influence corporate climate; hence, managers can control ethical behavior of their employees by changing the corporate ethical culture of functions where unethical behavior is commonplace (El-Kassar et al., 2017; Wimbush et al., 1997). To achieve this aim, at the first step, managers must assess the ethical culture of organizations and to do so they need to have access to valid instruments. We can expect that some dimensions of ethical climate/culture measures are highly predictive of certain unethical behaviors. Identifying those dimensions can shed more light on the procedures needed to control the ethical environment.

Most ethical climate and culture measures developed and widely used among academicians have been criticized (Mayer, 2014). The author suggests the ethical culture scale developed by Kaptein (2008) be tested in models since it has solid theoretical bases and is validated rigorously. The ethical culture construct developed in Kaptein's work is based on the Corporate Virtue Model and has eight dimensions: clarity, congruency of supervisors, congruency of management, feasibility, supportability, transparency, discussability, and sanctionability. We propose this ethical culture construct predicts the extent ethical marketing norms are accepted and followed in marketing departments. Such assumption is valid based on the literature that reports identified components of culture have an impact on ethical behavior. For instance, personal costs and external pressures affect ethical behaviors (Rest, 1984). Similarly, Staw and Szwajkowski (1975) also reported time pressure, scarce resources, competition, and personal costs are important factors. These factors have been covered in the feasibility dimension of Kaptein's culture construct.

Research has demonstrated that punishing ethical behavior and rewarding unethical conduct leads to more unethical behavior (Trevino et al., 1985). The interesting point is the stronger effect of punishing unethical behavior on deterrence than the effect of rewarding ethical behavior on encouraging positive behavior. Reward, punishment and reinforcement policies have been captured in sanctionability dimension. Nill (2007) maintained that supervisors can use "carrots and sticks" to control employee behavior. He regards pay raises, bonuses and public recognition as carrots and rebukes, fines, demotions and firings as carrots. Research has shown that organizations show leniency when dealing with unethical acts of top sales agents (Bellizzi and Hasty, 2003). This attitude can function as a carrot for marketing employees.

Deshpande et al. (2000) demonstrated the effect of supervisor and management behavior on the ethical behavior of employees. This is covered in supervisor and management congruity dimensions of construct. 
Whistle-blowing (Graham, 1986; Kaptein, 2011) and peer reports of wrong-doings decrease unethical conducts. These factors are captured in discussability dimension. Supportability dimension is the level that an organization creates support among employees to follow, stay committed and identify with rules. According to social exchange theory (Jehn, 1997), employees who feel they are valued and supported will more likely resonate with codes and policies. Transparency and visibility of behavior also affect the probability of individual' getting involved in unethical acts. (Hollinger and Clark, 1983).

Hunt and Vitell (1986) developed a general theory of marketing ethics. In their seminal work, both individual experiences and environment (organizational, cultural, and industry) affect how ethical people perceive the situations and what alternatives and consequences they consider in each case. These assessments along with deontological and teleological evaluations form ethical judgments, which in turn lead to intentions and behavior. In their model behavior is restricted by situational constraints and feeds back to personal experience and completes the loop. Hunt and Vitell (2006) highlight the key point that the H-V model is a process model of ethical decision making, not a causal model, meaning that constructs must be developed to measure the components of the model. The marketing norms measure developed by Vitell et al. (1993) captures the deontological component of the model. The culture construct of Kaptein (2008) covers perceived consequences as well as the probability and desirability of consequences. According to Hunt and Vitell (2006), for deontologists, certain aspects of actions is determinant of what is wrong or right, and circumstances cannot change their decision. For instance, a deontologist will believe that misleading sales tactics should be avoided no matter what the situation is; in contrast, a teleologist will compare negative consequences (fine paid if caught, negative reputation for the firm, unfavorable customer relationship) and benefits (salary and commission) and will decide based on the side that outweighs the other. Authors suggest that we must assume people are normally in between the strict deontological-strict teleological spectrum. Within the marketing context, a strict deontologist might view discriminating in charging different prices as inherently unethical and would restrain from this unethical practice. In contrast, a strict teleologist might evaluate whether probable positive consequences for himself and the firm outweigh likely negative consequences (negative reputation and punishments). In the next section, we discuss a set of propositions regarding the effects of cultural precedents on marketing norms.

\section{Propositions}

\section{Cultural Precedents}

Levy and Slavin (2014) mention that three conditions encourage unethical behavior: (a) People are intrinsically inclined to do unethical acts, (b) there exists an opportunity for unethical act, and (c) benefits outweigh negative consequences. Little work has been done, however, to take these factors into account with regard to unethical practices of 4Ps. Moreover, investigating the effect of engaging in unethical acts in 4Ps on stakeholders leaves room for research since the attention to the topic has not been balanced, and except for promotion and advertisement, other marketing mix variables (product, price and distribution management) have attracted limited research focus (Laczniak and Murphy, 2006).

Mayer (2014) maintains that three is a dearth of works on the impact of precedents on the ethical culture of an organization. Schaubroeck et al. (2012) were among the few who shed more light on this matter. A positive relationship between formal training and ethical culture stemmed from the former work and a positive relationship between ethical leadership and ethical culture demonstrated in the latter. Key (1999) suggests that how employees are treated impacts their perceptions of ethics in organizations and these estimations, in turn, influence their behavior. This occurs because how they are treated clouds their judgment about the overall culture of the organization. To the best of our knowledge, no research has investigated the accuracy of this proposition. According to Mayer (2014), ethical culture "is generally positively related to job attitudes and ethical behavior and negatively related to unethical conduct and experienced ambiguity." Moreover, individuals' perceptions of organizational justice affect how they see corporate ethical culture (Trevino, 2001). Therefore, we propose:

Proposition 1: Training, job satisfaction, organizational/distribution justice, and ethical leadership predict the ethical culture of the organization and the acceptance of marketing norms.

\section{Contextual Moderators}

\section{Ethical Optimism}

Academics have included the opportunity variable in their studies of ethical optimism. Vitell and Davis (1990) reported that for MIS professionals ethical behavior was not necessary for success. They demonstrated that although the opportunity for unethical behavior exists for respondents, they seldom show 
ISSN (online) - 2520-6311; ISSN (print) - 2520-6761

such behaviors. They also show that successful managers were generally more ethical. They use a single item to measure the opportunity for unethical behavior and another item for the existent of unethical behavior among managers in the firms. They later combine these two items into one scale and call it the extent of unethical behavior. Opportunity to do unethical behavior was first coined in the work of Ferrell and Gresham's model (1985), it was reported to be a better predictor of unethical behavior than peer or personal factors. In their model, the opportunity is controlled by codes, policies, rewards, and punishments. The opportunity for unethical behavior is more in unclear or unethical climates (Peterson, 2002). "Ethical Optimism" measure was first stemmed from the work of Hunt et al. (1984). Authors used a six-item scale (two items for opportunity and unethical behaviors, four items for success and specific unethical behavior). Deshpande et al. (2000) also noted that conducts of successful managers appear to be influential in the ethical behavior of others since they act as role models for employees (Paine, 1994). According to Deshpande et al. (2000), “... any un-reprimanded unethical behavior on managers' part will send a signal that unethical acts are acceptable standards of corporate behavior". In Hunt et al.'s work (1984), the opportunity for success is not perceived as a latent motive for unethical behavior among managers. Past studies on ethical optimism have focused on managers and their beliefs. However, Kincaid et al. (2008) examined the actions of management and their effect on the ethical optimism of workers in the restaurant industry and found significant differences between ethnic groups, men and women, and length of employment.

\section{Organizational Factors}

Trevino (1986) found that democratic cultures encourage ethical behavior by motivating people to take responsibility for their behavior. Jones (1991) posits that organizational factors may distort the ethical intentions of individuals. Hegarty and Sims (1979) stated that research has found organizations create reward systems that are so closely tied to monetary objectives, such as profits, and that ethical behavior only matters when legal requirement needs to be met. Middle managers in marketing departments are pressed to make sales at minimum costs. Thus, they are more likely to resort to unethical practices. Using unethical practices and oblivious of the repercussions in an attempt to make more profits, employees can get the results but at great costs. Examples of the Watergate scandal and the Lockheed case demonstrate the point (Lee, 1981). Competition (Vadera et al., 2014; Cai et al., 2009), bonus and commission (Walker et al., 2013), promotion (Pierce and Snyder, 2015), importance of stakeholders (Hunt and Vitell, 1986), public recognition (Adebayo, 2005) are among other organization-related factors that contribute to unethical behavior and in our model are proposed to moderate the relationship between cultural precedents and marketing norms acceptance. Vadera et al. (2014) found that moral identity moderates the effect of competition on unethical behavior and that impaired moral awareness mediates their relationship. In a laboratory experiment setting, Schweitzer et al. (2004) investigated the role of goal setting on unethical behavior. They realized that "people with unmet goals (both economic and noneconomic) were more likely to engage in unethical behavior than people attempting to do their best". They conclude that if people feel they are pressed to meet some unachievable goals, they are more likely to engage in unethical conducts. The negative effect of goal setting on organization ethics and culture has also been analyzed in Ordonez et al. (2009). If customers demand adherence to ethics, unethical behavior leads to employees' career failure and job dissatisfaction resulting from conflicts with customers. (Pierce and Snyder, 2015).

\section{Industry Factors}

Vitell et al. (1993) suggest considering the industry environment as another moderator, besides the organizational environment, professional environment, and personal characteristics, when investigating factors that affect ethical decision making. The use of ethics codes could depend on industry practices (Weaver, 1993; Schlegelmilch and Robertson, 1995; White and Montgomery, 1980). The social and industrial culture in which marketers work is influential in their demonological norms (Singhapakdi and Vitell, 1990). Marketing norms discussed in this paper have roots in deontology. Thus, we propose social and industry environment moderate the effect of corporate culture on marketing norms prevalence.

All in all, in our proposed model, contextual factors moderate the relationship between cultural precedents and marketing norms. Trevino and Klebe (1986) state that "Situational variables arising from the immediate job context and the broader organizational culture also moderate the cognition/behavior relationship". Corporate culture affects how people perceive ethical situations (Hunt and Vitell, 1986). Hence, we propose situational factors moderate the relationship between cultural precedents and marketing norms' acceptance:

Proposition 2: Contextual factors (ethical optimism, organizational, and industry factors) moderate the relationship between cultural precedents and marketing-related norms. 


\section{Individual Moderators}

Hunt and Vitell (1993) state that "belief system" is likely to guide behavior in ethical situations, and they further depict various elements that make up the organizational environment such as informal norms, formal codes of ethics and the enforcement of codes that impact on decision making in ethical situations. Vitell et al. (1993) posit that the idealism/relativism paradigm developed by Forsyth $(1980,1992)$ is parallel to the two dimensions of moral philosophies: deontology and teleology (correspondingly). Thus, we can assume that idealists (and similarly deontologists) are more likely to accept marketing norms. Consequently, we postulate that the moral philosophy of individuals affects the association between culture and marketing norms. Similarly, we can argue that the perception and response of people to marketing norms are affected by their moral philosophy. As opposed to teleologists, deontologists may respond strongly to the marketing norms.

Individual factors are important in the evaluation and resolution of ethical issues (Murphy et al., 2005). Individuals' perceptions of how ethical the culture is have been reported to be affected by a set of individual factors: demography, age (England, 1978), gender, personality traits (Nelson and Gilbertson, 1991), ethical education, sex, experience (Borkowski and Ugras, 1992), nationality (Hegarty and Sims, 1979), and religion (Barnett et al., 1996). Numerous studies have investigated the effect of individual moderators on unethical behavior. Hegarty and Sims (1979) demonstrated that personal desire for wealth was a significant covariate of unethical behavior; however, organizational profit goals could not predict unethical behavior. In their study, they also showed four personality traits (locus of control, Machiavellianism, economic and political value orientation) that were positively related to unethical behavior. Unlike other studies, their work did not find a significant relationship between sex and unethical behavior. Some studies also propose that individual factors affect how ethical people perceive a situation; a perception that, in turn, affects their reaction to it. Personal moral development and philosophy determine "why different people perceive issues with varying intensity" (Robin et al., 1996). Therefore, we propose:

Proposition 3: Individual factors (i.e., moral philosophies, demography, and personality traits) moderate the relationship between cultural precedents and marketing-related norms.

The suggested propositions are illustrated in Figure 1.

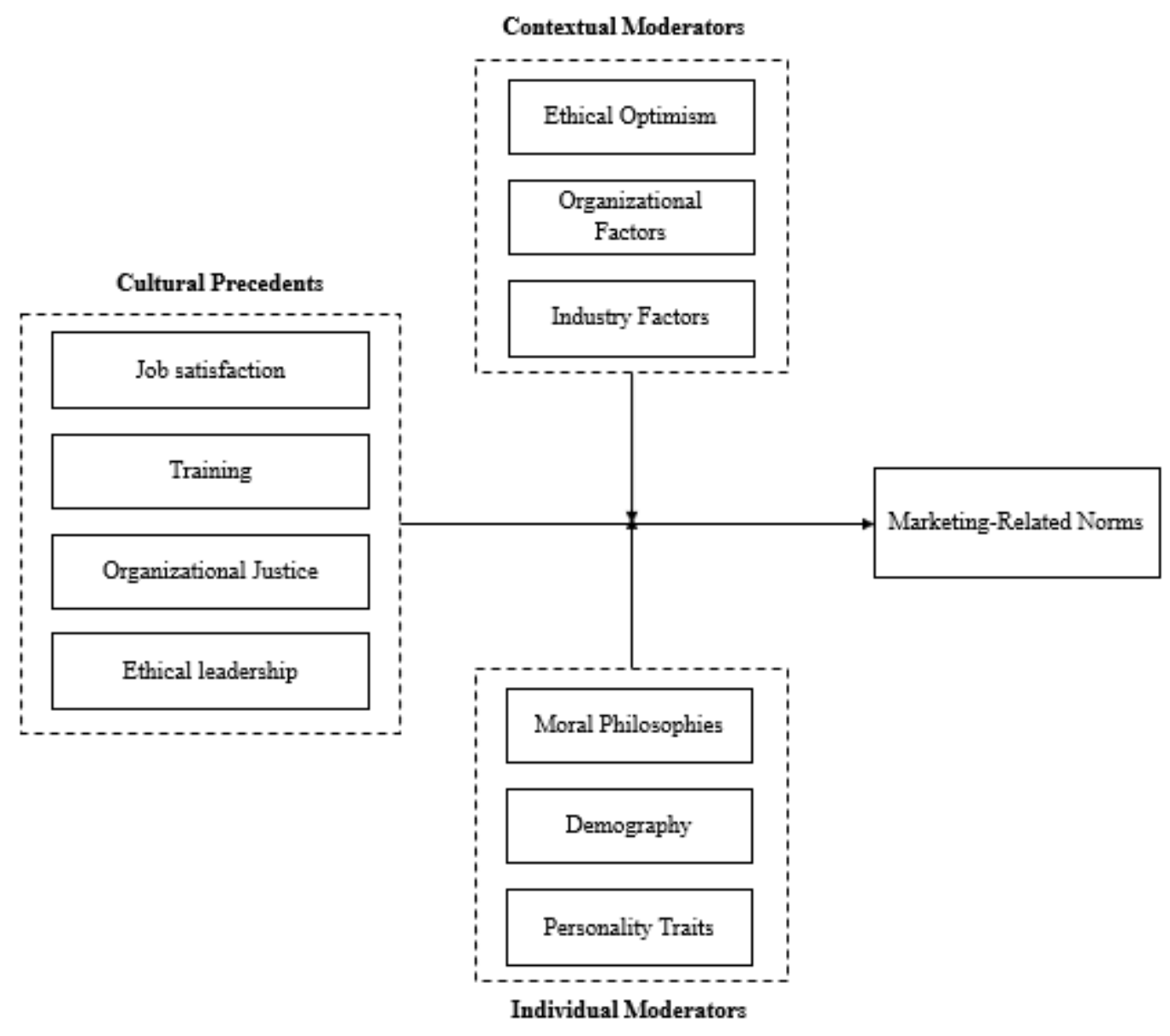

Source: Developed by the authors

Figure 1. Proposed Model 
Business Ethics and Leadership, Volume 3, Issue 3, 2019

\section{Conclusions and Recommendations}

In this paper, we proposed that cultural precedents can lead to the ethical culture of an organization. Ethical culture helps to acceptance of ethical marketing norms. We also proposed that contextual and individual factors moderate the relationship between ethical culture and ethical marketing norms. According to our model, if managers need to improve the ethical practices of 4P (i.e., price, product, place, and promotion), they should focus on the culture of their organizations as predictors of those practices and the effects of moderating factors on ethical marketing norms. Managers should work on training, ethical leadership and organizational/distributive justice to build the ethical culture in their organizations. In this way, they can increase the chance of acceptance of marketing norms in the organization. Managers should be aware of the role of moderating factors such as demography and personal traits of the people who they work with. By considering these roles, they can better implement the marketing norms in their organizations. If they become successful in applying these norms, they can move toward success in their business. This success can be defined as customers' trust and satisfaction (therefore, higher sales and profits) and employees' commitment (therefore, higher performance and lower costs) through an ethical environment.

\section{References}

1. Adebayo, D. O. (2005). Ethical attitudes and prosocial behaviour in the Nigeria police: Moderator effects of perceived organizational support and public recognition. Policing: An International Journal of Police Strategies \& Management, 28(4), 684-705.

2. Barnett, T., Bass, K., \& Brown, G. (1996). Religiosity, ethical ideology, and intentions to report a peer's wrongdoing. Journal of Business Ethics, 15(11), 1161-1174.

3. Bellizzi, J. A., \& Hasty, R. W. (2003). Supervising unethical sales force behavior: how strong is the tendency to treat top sales performers leniently? Journal of Business Ethics, 43(4), 337-351.

4. Borkowski, S. C., \& Ugras, Y. J. (1992). The ethical attitudes of students as a function of age, sex and experience. Journal of Business Ethics, 11(12), 961-979.

5. Cai, H., Liu, Q., \& Xiao, G. (2009). Does competition encourage unethical behavior? The case of corporate profit hiding in China. Economic Journal, 119(4), 764-95.

6. Deshpande, S. P., George, E., \& Joseph, J. (2000). Ethical climates and managerial success in Russian organizations. Journal of Business Ethics, 23(2), 211-217.

7. El-Kassar, A. N., Yunis, M., \& El-Khalil, R. (2017). The mediating effects of employee-company identification on the relationship between ethics, corporate social responsibility, and organizational citizenship behavior. Journal of Promotion Management, 23(3), 419-436.

8. England, G. W. (1978). MANAGERS AND THEIR VALUE-SYSTEMS-5-COUNTRY COMPARATIVE-STUDY. Columbia Journal of World Business, 13(2), 35-44.

9. Ferrell, O. C., \& Gresham, L. G. (1985). A contingency framework for understanding ethical decision making in marketing. Journal of marketing, 49(3), 87-96.

10.Ferrell, L., \& Ferrell, O. C. (2009). An enterprise-wide strategic stakeholder approach to sales ethics. Journal of Strategic Marketing, 17(3-4), 257-270.

11.Forsyth, D. R. (1980). A taxonomy of ethical ideologies. Journal of Personality and Social psychology, 39(1), 175.

12.Forsyth, D. R. (1992). Judging the morality of business practices: The influence of personal moral philosophies. Journal of Business Ethics, 11(5-6), 461-470.

13.Graham, J. W. (1986). Principled organizational dissent: A theoretical essay. Research in organizational behavior, 8 (JAI Press, Greenwich, CT), 1-52.

14.Hegarty, W. H., \& Sims, H. P. (1979). Organizational philosophy, policies, and objectives related to unethical decision behavior: A laboratory experiment. Journal of Applied Psychology, 64(3), 331.

15.Hollinger, R. C., \& Clark, J. P. (1983). Deterrence in the workplace: Perceived certainty, perceived severity, and employee theft. Social forces, 62(2), 398-418.

16.Hoogenboom, A. B., Pheijffer, M., \& Karssing, E. D. (2013). Gorillas, markets and the search for economic values: Rethinking Lehman Brothers and the global financial crises. Assen: Royal Van Gorcum, 105-114.

17.Hunt, S. D. (1991). Modern marketing theory: Critical issues in the philosophy of marketing science. South-Western Pub.

18.Hunt, S. D., \& Vitell, S. J. (1993). The general theory of marketing ethics: A retrospective and revision. Ethics in marketing, edited by N. C. Smith and J. A. Quelch, 775-784. Homewood, IL: Irwin. 
Business Ethics and Leadership, Volume 3, Issue 3, 2019 ISSN (online) - 2520-6311; ISSN (print) - 2520-6761

19.Hunt, S. D., \& Vitell, S. J. (2006). The general theory of marketing ethics: A revision and three questions. Journal of macromarketing, 26(2), 143-153.

20.Hunt, S. D., \& Vitell, S. (1986). A general theory of marketing ethics. Journal of macromarketing, 6(1), 5-16.

21.Hunt, S. D., Chonko, L. B., \& Wilcox, J. B. (1984). Ethical problems of marketing researchers. Journal of Marketing Research, 21(3), 309-324.

22.Jehn, K. A. (1997). A qualitative analysis of conflict types and dimensions in organizational groups. Administrative science quarterly, 42(3), 530-557.

23.Jones, T. M. (1991). Ethical decision making by individuals in organizations: An issue-contingent model. Academy of management review, 16(2), 366-395.

24.Kaptein, M., \& Schwartz, M. S. (2008). The effectiveness of business codes: A critical examination of existing studies and the development of an integrated research model. Journal of Business Ethics, 77(2), 111-127.

25.Kaptein, M. (2008). Developing and testing a measure for the ethical culture of organizations: The corporate ethical virtues model. Journal of Organizational Behavior: The International Journal of Industrial, Occupational and Organizational Psychology and Behavior, 29(7), 923-947.

26.Kaptein, M. (2011). From inaction to external whistleblowing: The influence of the ethical culture of organizations on employee responses to observed wrongdoing. Journal of Business Ethics, 98(3), 513-530.

27. Key, S. (1999). Organizational ethical culture: real or imagined? Journal of Business Ethics, 20(3), $217-225$.

28.Kincaid, C. S., Baloglu, S., \& Corsun, D. (2008). Modeling ethics: The impact of management actions on restaurant workers' ethical optimism. International Journal of hospitality management, 27(3), 470-477.

29.Laczniak, G. R., \& Murphy, P. E. (2006). Normative perspectives for ethical and socially responsible marketing. Journal of Macromarketing, 26(2), 154-177.

30.Lau, P. Y. Y., Tong, J. L. T., Lien, B. Y. H., Hsu, Y. C., \& Chong, C. L. (2017). Ethical work climate, employee commitment and proactive customer service performance: Test of the mediating effects of organizational politics. Journal of Retailing and Consumer Services, 35(July 2016), 20-26.

31.Lee, K. H. (1981). Ethical beliefs in marketing management: A cross-cultural study. European Journal of Marketing, 15(1), 58-67.

32.Levy, C. S., \& Slavin, S. (2014). Guide to ethical decisions and actions for social service administrators: A handbook for managerial personnel. Routledge.

33.Mayer, D. M. (2014). A review of the literature on ethical climate and culture. The Oxford handbook of organizational climate and culture, 415.

34.Murphy, P. E., Laczniak, G. R., Bowie, N. E., \& Klein, T. A. (2005). Ethical marketing. Upper Saddle River, NJ: Pearson Prentice Hall.

35. Nelson, G., \& Gilbertson, D. (1991). Machiavellianism revisited. Journal of Business Ethics, $10(8), 633-639$.

36.Nill, A., \& Schibrowsky, J. A. (2007). Research on marketing ethics: A systematic review of the literature. Journal of macromarketing, 27(3), 256-273.

37.Ordóñez, L. D., Schweitzer, M. E., Galinsky, A. D., \& Bazerman, M. H. (2009). Goals gone wild: The systematic side effects of overprescribing goal setting. Academy of Management Perspectives, 23(1), 6-16.

38.Paine, L. S. (1994). Managing for organizational integrity. Harvard business review, 72(2), $106-117$.

39.Peterson, D. K. (2002). The relationship between unethical behavior and the dimensions of the ethical climate questionnaire. Journal of Business Ethics, 41(4), 313-326.

40.Pierce, L., \& Snyder, J. A. (2015). Unethical demand and employee turnover. Journal of business ethics, 131(4), 853-869.

41.Rest, J. R. (1984). The major components of morality. Morality, moral behavior, and moral development, New York: Wiley, 24-38.

42.Robin, D. P., Reidenbach, R. E., \& Forrest, P. J. (1996). The perceived importance of an ethical issue as an influence on the ethical decision-making of ad managers. Journal of Business Research, 35(1), 17-28.

43.Schaubroeck, J. M., Hannah, S. T., Avolio, B. J., Kozlowski, S. W., Lord, R. G., Treviño, L. K., ... \& Peng, A. C. (2012). Embedding ethical leadership within and across organization levels. Academy of Management Journal, 55(5), 1053-1078.

44.Schlegelmilch, B. B., \& Robertson, D. C. (1995). The influence of country and industry on ethical perceptions of senior executives in the US and Europe. Journal of International Business Studies, 26(4), 859-881.

45.Schlegelmilch, B. B., \& Öberseder, M. (2010). Half a century of marketing ethics: Shifting perspectives and emerging trends. Journal of Business Ethics, 93(1), 1-19.

46.Schweitzer, M. E., Ordóñez, L., \& Douma, B. (2004). Goal setting as a motivator of unethical behavior. Academy of Management Journal, 47(3), 422-432. 
Business Ethics and Leadership, Volume 3, Issue 3, 2019

ISSN (online) - 2520-6311; ISSN (print) - 2520-6761

47.Singhapakdi, A., \& Vitell, S. J. (1990). Marketing ethics: Factors influencing perceptions of ethical problems and alternatives. Journal of Macromarketing, 10(1), 4-18.

48.Staw, B. M., \& Szwajkowski, E. (1975). The scarcity-munificence component of organizational environments and the commission of illegal acts. Administrative Science Quarterly, 20(3), 345-354.

49.Trevino, L. K., Sutton, C. D., \& Woodman, R. W. (1985, August). Effects of reinforcement contingencies and cognitive moral development on ethical decision-making behavior. In annual meeting of the Academy of Management, San Diego.

50.Trevino, L. K., \& Weaver, G. R. (2001). Organizational justice and ethics program "follow-through": Influences on employees' harmful and helpful behavior. Business Ethics Quarterly, 11(4), 651-671.

51.Trevino, L. K. (1986). Ethical decision making in organizations: A person-situation interactionist model. Academy of management Review, 11(3), 601-617.

52.Vadera, A. K., Srivastava, V., Aquino, K., \& Chandrashekarrao, P. (2014). Effect of competition on unethical behaviors. In Academy of Management Proceedings (2014(1), 13298). Briarcliff Manor, NY 10510: Academy of Management.

53.Vitell, S. J., \& Davis, D. L. (1990). Ethical beliefs of MIS professionals: The frequency and opportunity for unethical behavior. Journal of Business Ethics, 9(1), 63-70.

54.Vitell, S. J., Rallapalli, K. C., \& Singhapakdi, A. (1993). Marketing norms: The influence of personal moral philosophies and organizational ethical culture. Journal of the Academy of Marketing Science, 21(4), 331.

55.Vitell, S. J., Nwachukwu, S. L., \& Barnes, J. H. (1993). The effects of culture on ethical decision-making: An application of Hofstede's typology. Journal of business Ethics, 12(10), 753-760.

56.Walker, K. B., \& Fleischman, G. M. (2013). Toeing the line: The ethics of manipulating budgets and earnings. Management Accounting Quarterly, 14(3), 18-24.

57.Weaver, G. R. (1993). Corporate codes of ethics: Purpose, process and content issues. Business \& Society, 32(1), 44-58.

58. White, B. J., \& Montgomery, B. R. (1980). Corporate codes of conduct. California management review, 23(2), 80-87.

59.Wimbush, J. C., Shepard, J. M., \& Markham, S. E. (1997). An empirical examination of the multidimensionality of ethical climate in organizations. Journal of Business Ethics, 16(1), 67-77. 